UDK 528.73

\title{
COMPARISON BETWEEN DIGITAL PHOTOGRAMMETRIC SYSTEMS
}

\author{
Birutė Ruzgienė \\ Dept of Geodesy and Cadastre, Vilnius Gediminas Technical University, \\ Sauletekio al.11, LT-10223 Vilnius, Lithuania \\ E-mail: Birute.Ruzgiene@ap.vtu.lt \\ Received 1202 2007, accepted 29062007
}

\begin{abstract}
The usage of Digital Photogrammetric Systems leads to increasing the mapping capabilities and efficiency through a full automation or in some cases half automation of mapping procedures. The digital image processing has possibility to improve the photogrammetric mapping implementation concerning the functionality and performance results relation. The goal of research is to investigate the functionality, flexibility and efficiency of two Digital Photogrammetric Mapping Systems for 3D surface modelling from aerial photographs. The experimental photogrammetric measurements have been carried out using DDPS software (Photogrammetric Package for Digital Aerial Photographs) as well as DPW (Digital Photogrammetric Workstation) LISA FOTO. The results of comparison between these two photogrammetric software show capabilities and possibilities for getting best results in digital photogrammetric processing. The analysis demonstrates that DDPS does not fulfil fully a typical workflow in digital photogrammetric mapping. However, the digital surface modelling is more efficient in time-consuming. There is no doubt that DPW LISA FOTO together with image processing module LISA BASIC have more priorities, potentials and leads to wide applications. Despite this fact, DPW work is more complicated than DDPS in such aspects as stereo model creation, interpretation capabilities etc. The best digital photogrammetric mapping work flow could be achieved when integrating these two systems for getting a more efficient and highest productivity.
\end{abstract}

Keywords: Digital Photogrammetric Workstation, orientation procedures, digital terrain model, image processing, orthophoto generation, stereoscopic model.

\section{Introduction}

The digital photogrammetry is a technology allowing to determine the position of an object in a threedimensional space by data recorded not photographically but by electronic means. Such techniques used to get information about objects represented in photos and are fully digital workflow nowadays. Therefore the photogrammetric handling the images become easier and allows using these techniques also for nonphotogrammetrists-cartographers, geographers, forest engineers, geologists etc. The digital image processing technologies have a possibility to increase mapping efficiency when all procedures are automated.

The digital generation of orthophotos is one of the broadest product in photogrammetric application. However, digital photogrammetric technology can construct the geometry from two images of the same object captured from two different stations of view removing differences (parallaxes) as well. Thus, the stereoscopic vision becomes possible - the main task in photogrammetry has been achieved.

Many tasks of digital photogrammetry can be solved in close cooperation Geographic Information Systems. For example, digital orthophotos used to be very successfully incorporated as background information in GIS [1].
The solution of photogrammetric tasks mentioned above is based on Digital Photogrammetric Workstations that require powerful computers with fast processors for image processing, larger storage units, suitable graphic screen resolution etc.

Many manufacturers are offering digital photogrammetric workstations also incorporating 3D observations from digital stereo pairs. Three main manufacturers offered by photogrammetric workstations are: Intergraphs, Huntsville offers the ImageStation, USA; Leica, Heerbrugg, Switzerland, offers DPV; Matra, France - TRASTER TIO.

The determination which digital mapping package is better to leads to reduction of costs and time for collecting 3D data sets and constructing topographic maps by photogrammetric treatment of aerial photographs.

The goal of research is to compare the functionality from two Digital Photogrammetric Mapping Systems investigating the two systems by experiments and demonstrating the possibility of the integration for getting highest photogrammetric mapping productivity.

The experimental photogrammetric measurements have been carried out by DDPS software (Photogrammetric Package for Digital Aerial Photographs), Belgium-Poland as well as DPW (Digital Photogrammetric Workstation), LISA FOTO with image processing module LISA BASIC, Germany. 


\section{Some aspects of methodology}

Generally, the Digital Photogrammetric Workstation is constructed in such a way that is able to provide the following functions [2]:

1. Stereo measurements-interactive stereo plotting, elevation data from digital terrain model;

2. Mono measurements - planimetric plotting;

3. Automatic generation of digital terrain models, contours

4. Generation of orthoimages;

5. Creation of orthophotos mosaics.

One of main steps in photogrammetric image procedure is an image matching when homologous points on the overlapping area of several images are automatically searched. Mostly, a technique is used, named Area Based Matching, based on pattern, target and search window, when points are identified if they have similar grey values. The pattern window is the window surrounding the matched pixel on the left image. It is very important that a user chooses properly its size width and height. It is related to the intended accuracy of searched points.

Search window involves matched pixels for which correlation used is to be evaluated - the central pixels for different searched target windows. The size of search window depends on quality of the approximation of the homologous point position. The target window is the window surrounding the matched pixels on the right image. Its size should be the same as that of pattern window.

a)
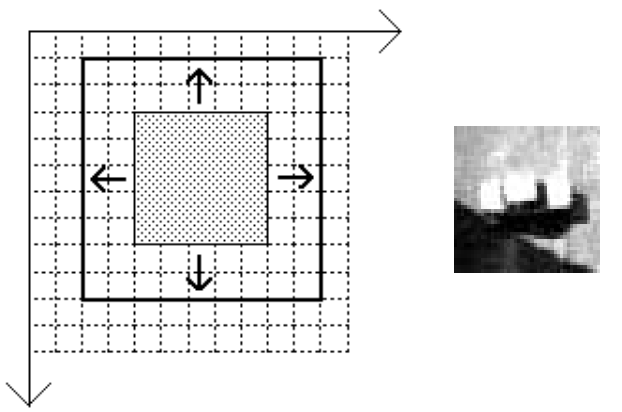

b)

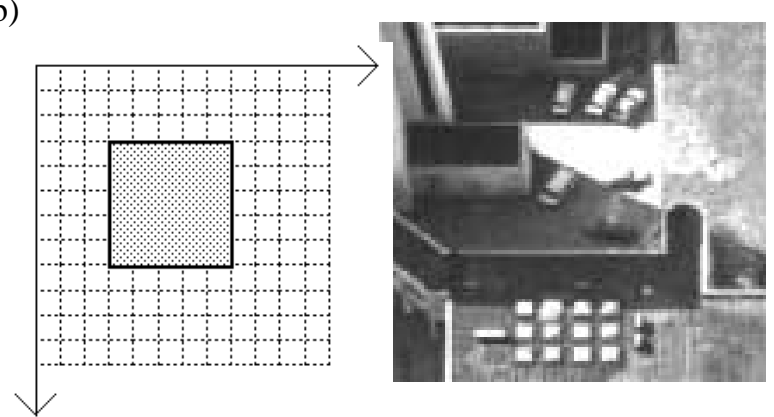

Fig 1. Principle of image correlation: a) pattern, b) search position of pattern in search window
Fig 1 shows the description of pattern (target) and search windows.

For determining the best position in search window, the pattern is moved pixel by pixel and the correlation function in every position is calculated. A correlation coefficient is determined for evaluating grey values between the pattern and the target window by formulae [3]:

$$
\rho_{(i, j)}=\frac{\sigma_{12}(i, j)}{\sigma_{1} \sigma_{2}(i, j)},
$$

where

$$
\begin{aligned}
& \bar{g}_{1}=\frac{1}{N} \sum_{k} \sum_{l} g_{1}(k, l), \\
& \bar{g}_{2}(i, j)=\frac{1}{N} \sum_{k} \sum_{l} g_{2}(i+k, j+l), \\
& \sigma_{1}=\sqrt{\sum_{k} \sum_{l}\left(g_{1}(k, l)-\bar{g}_{1}\right)^{2}}, \\
& \sigma_{2}(i, j)=\sqrt{\sum_{k} \sum_{l}\left(g_{2}(i+k, j+l)-\bar{g}_{2}(i, j)\right)^{2}}, \\
& \sigma_{12}(i, j)=\sum_{k=-2}^{+2} \sum_{l=-2}^{+2}\left(g_{1}(k, l)-\bar{g}_{1}\right)\left(g_{2}(i+k, j+l)-\bar{g}_{2}(i, j)\right),
\end{aligned}
$$

$\sigma_{1}-$ standard deviation of pixel grey value in target window,

$\sigma_{2}(i, j)$ - standard deviation of pixel grey value in search window,

$\sigma_{12}(i, j)$ - covariation,

$g_{1}-$ pixel grey value in target window,

$g_{2}-$ pixel grey value in search window,

$k, l-$ rows and columns in target window,

$N$ - the number of pixels in pattern and target windows,

$\bar{g}_{1}-$ mean pixel's grey value in target window,

$\bar{g}_{2}-$ mean pixel's grey value in search window.

Correlation coefficient gets value from 0 to 1 . When correlation coefficient equals 0 , there is no correlation, and if $1-$ there is a perfect correlation. The homologous point on the left image will be the same in the search window of right image, when correlation coefficient gets a maximal value.

Sometimes the identified points in stereo images are not exactly the homologous ones. In these cases DDPS allows to correct their position manually.

\section{Applications and analysis}

The full photogrammetric procedures have been performed for determining the main criteria in using digital photogrammetric systems for application to get optimal results with a highest effectiveness. 


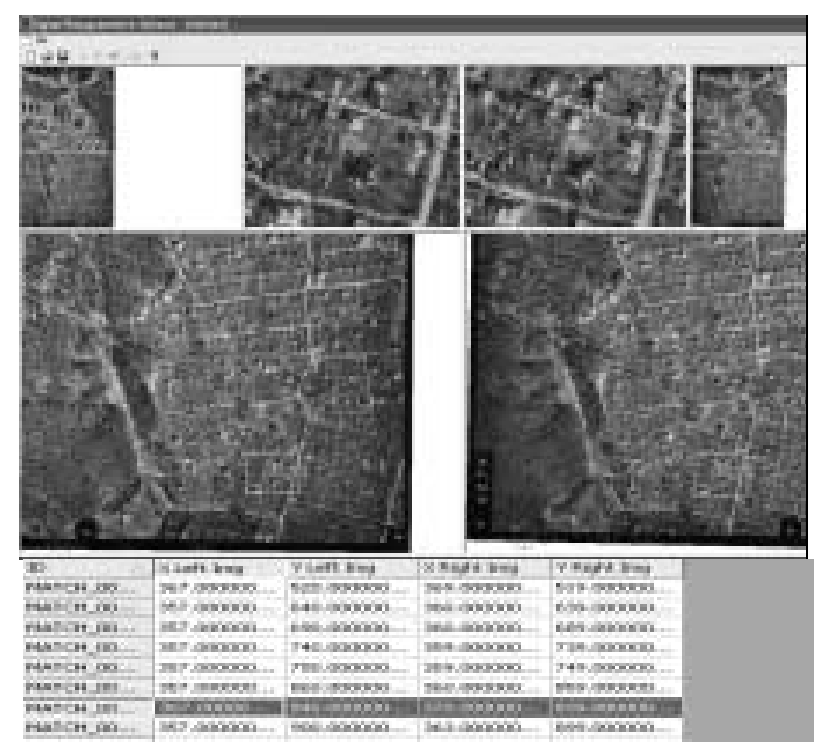

Fig 2. Fragment of results from automatic searching the homologous points

Image material - the aerial photos taken by analogue aerial camera ( $R M K T O P)$ in an usual format of $23 \times 23 \mathrm{~cm}$ were used for processing. The analogue diapositives were converted into digital format with pixel size of $14 \mu \mathrm{m}$. Camera calibration certificate was at the researcher's disposal.

The complete workflow of photogrammetric digital images processing was realised on a Digital Photogrammetric System DDPS [4] and Digital Photogrammetric Workstation LISA [2]. Digital photogrammetric software LISA FOTO is an extension of raster GIS software LISA BASIC with a lot of possibilities in image processes, developed at the University of Hannover, (Germany).

Fig 2 shows extraction from image matching results in DDPS.

The creation of Digital Terrain Model (DTM) has been made via image matching using LISA FOTO as well. Fragment from matching procedures (cf paragraph 2) can be seen in Fig 3.

After experimental photogrammetric processing of stereo models (15 aerial photographs), the comparison between two digital photogrammetric systems has been based at first on requirements, possibilities and functionalities of the software.

Requirements for operating the software DDPS:

- System processes digital images with 8 bits/pixel - grey level;

- Input file format only BMP;

- Images must be taken with a metric camera, ie needs for camera calibration certificate;

- Sufficient number of control points (minimal 6) observable on stereo photos;

- PC characteristics (minimal): processor frequency $-400 \mathrm{MHz}$, main memory (RAM) - $256 \mathrm{MB}$, hard disk - 1 GB, graphic resolution - 1024 x 768, screen size - 17", mouse with 3 buttons. a)
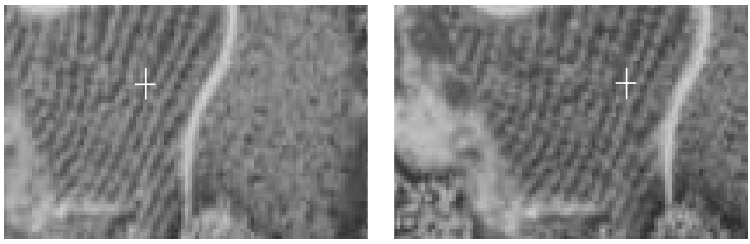

b)
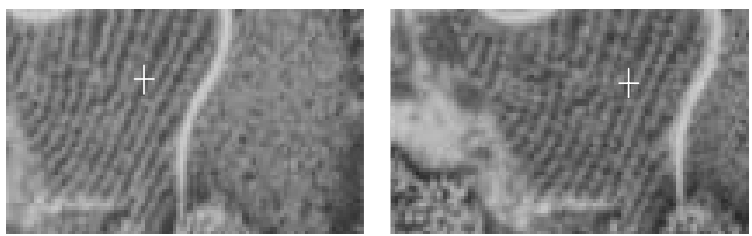

Fig 3. Correlation of images: a) images are too close to each other, b) correct position

DDPS production possibilities are: inner orientation, exterior orientation, epipolar resampling, image matching, generation of DEM, orthorectification, VRML model generation. The main functionalities in DDPS are: to move in the images, to track down points on the images, to move in the charts, to make a zoom, to estimate the duration of specific procedures by threads.

The used digital photogrammetric software LISA consists of package with 3 modules:

LISA BASIC - raster GIS software with all possibilities in image processing;

LISA FOTO - digital photogrammetric workstation;

$B L U H$ - professional bundle block adjustment software adapted to aerial triangulation.

The requirements for LISA functionality:

- The max size per image is limited to $10 \mathrm{MB}$;

- Only grey scale images can be processed;

- Tools for creation and handling a database for geocoded images are not available.

The differences in photogrammetric processing possibilities, using the above-mentioned both software, are presented in Table 1.

Table 1. Comparison between two digital photogrammetric systems regarding two typical workflows

\begin{tabular}{|l|c|c|}
\hline \multicolumn{1}{|c|}{$\begin{array}{c}\text { Typical photogrammetric } \\
\text { procedures }\end{array}$} & DDPS & $\begin{array}{c}\text { LISA } \\
\text { FOTO }\end{array}$ \\
\hline Data inputs: & + & + \\
Scanned photographs & - & + \\
Images from digital camera & $+/-$ \\
Camera calibration parameters & + & + \\
Control points & + & + \\
\hline Interior orientation & + & \\
\hline Exterior orientation: & - & + \\
Aerial triangulation & + & - \\
Relative orientation & - & + \\
Model definition for each & & \\
image & + & + \\
\hline Surface modelling & - & + \\
\hline Vector data collection & + & + \\
\hline Ortho-images creation & - & + \\
\hline Mosaics & & \\
\hline
\end{tabular}


Table 2. Comparison between two systems in image processing per model regarding time consuming

\begin{tabular}{|c|c|c|}
\hline \multirow{2}{*}{$\begin{array}{c}\text { Components of image } \\
\text { processing }\end{array}$} & \multicolumn{2}{|c|}{ Average duration, min } \\
\hline & DDPS & $\begin{array}{c}\text { LISA } \\
\text { FOTO }\end{array}$ \\
\hline $\begin{array}{l}\text { Inner orientation: } \\
\text { navigation and fiducial } \\
\text { marks identification }\end{array}$ & 1 & 2 \\
\hline Relative orientation & 8 & - \\
\hline Absolute orientation & 20 & 30 \\
\hline Image matching & 5 & 4 \\
\hline DEM, DTM creation & 1,5 & 2 \\
\hline Orthophoto generation & 1 & 2 \\
\hline Total & 36,5 & 40 \\
\hline
\end{tabular}

The investigation of time consuming and geometric accuracy in each main stages of photogrammetric workflow has been done as well. The results are presented in Tables 2, 3 .

LISA software allows modifying the moving (driving) speed of images when images are displayed, eg in orientation procedures. Despite of that, images management in DDPS is more flexible and easier. Thus, the orientation procedures by the LISA FOTO requires more time than by the DDPS.

In relative orientation with DDPS there was measured 12 Gruber points (when minimal number is 6) on the left and right images for obtaining more accurate results; however, the labour time increases.

The time for points navigation and accuracy of transformation from model coordinates to ground coordinates (absolute orientation) results very much depends on photogrammetric tie points (getting from aerial triangulation at the experimental project [5]) interpretable. About $20 \%$ control points are not possible to identify with a highest accuracy, ie they are not exactly determinable in grey values raster images.

Image matching time depends on selected parameters such as: sizes of target and search windows, dimension of cells and steps in images matching etc.

DEM and orthophoto generation time significantly depends on steps used in interpolation.

The investigation of accuracy has been done at the main images of photogrammetric processing procedures.

Performing inner orientation in LISA FOTO there is a possibility to use option "Subpixel improvement", and then an automatic centring onto the fiducial marks is realised. Thus, activating this option, fiducial marks are identified with subpixel accuracy.

Evaluating accuracy of absolute orientation about $10 \%$ blunders were found. The main reason of that is in difficulties in point's identification.

The images matching results in not very rough and not very dense of high buildings experimental area show not too a large number of wrong points - the points with different positions in left and right images. About $5 \%$ of these points have been corrected or deleted (particularly at image edges) manually.
Table 3. Comparison between two systems in image processing per model regarding the investigation accuracy

\begin{tabular}{|c|c|c|}
\hline \multirow{2}{*}{$\begin{array}{c}\text { Components of image } \\
\text { processing }\end{array}$} & \multicolumn{2}{|c|}{ Accuracy } \\
\hline & DDPS & $\begin{array}{c}\text { LISA } \\
\text { FOTO }\end{array}$ \\
\hline $\begin{array}{l}\text { Inner orientation: } \\
\text { max residuals from } \\
\text { measurements of fiducial } \\
\text { marks, mm }\end{array}$ & 0,007 & 0,014 \\
\hline $\begin{array}{l}\text { Relative orientation: } \\
\text { vertical parallax, mm } \\
\text { Model definition: } \\
\text { vertical parallax, mm } \\
\end{array}$ & 0,006 & 0,005 \\
\hline $\begin{array}{l}\text { Absolute orientation, m: } \\
\text { max residuals on } \\
\text { transformed control points }\end{array}$ & 0,070 & 0,079 \\
\hline Standard deviation & 0,040 & 0,042 \\
\hline DTM RMSE, $\mathrm{m}$ & 0,24 & 0,30 \\
\hline
\end{tabular}

DTM generation geometric accuracy depends on sufficient number of ground control points. The accuracy investigation has been based on the ground control points coordinates and photogrammetric tie point coordinates from aerial triangulation. The root mean square errors (RMSE) were calculated from the differences between coordinates of ground control points (coordinates of photogrammetric tie points were used as well) and coordinates of the same points after DTM generation in both digital systems. The difference in accuracy is not significant (Table 3 ). The received less accuracy from LISA FOTO could be explained by changing image resolution when processing images and dependence on the operator's experience.

The evaluation of geometric accuracy in each photogrammetric process using both digital systems shows fulfillment of the requirements for topographic mapping at scales 1:1000-1:2000 [6].

\section{Conclusions}

The analysis of two photogrammetric digital systems shows that usage of such digital technologies leads to a more flexible and efficient production of geodata.

After comparison of results it was defined that $D D P S$ is constructed in such a way, that is easier to use as well as image management is faster than in LISA FOTO. Additionally, interpretation capabilities are more effective, despite that the stereo viewing is not available.

However, without doubt, digital photogrammetric workstation LISA has a great advantage because of complete photogrammetric processing that needs in mapping technology. Application of DDPS has a priority in educational and didactic point of view when searching orthophotographic production workflow.

Regarding the capabilities of both photogrammetric systems, hybrid work flow has been foreseen: 

$D D P S$;

- Integration of aerial triangulation from LISA to

- Stereo feature extraction on the LISA is only possible;

- Digital orthophoto production is desirable in DDPS because of labour time reduction.

The investigated accuracy in separate stages of data processing using two digital photogrammetric systems differs not significantly; it appears because of dependence of the user's interpretable experience.

\section{References}

1. KONECNY, G. Geoinformation: remote sensing, photogrammetry and geographical information systems. London and New York: Taylor and Francis, 2003. 248 p.

2. LINDER, W. Digital photogrammetry. A Practical Course. Springer-Verlag, Berlin, Heidelberg, 2006. 214 p.

3. KRAUS, K. Photogrammetry. Vol 1. Fundamentals and Standard Processes. Köln: Dümmler, 2000. 396 p.

4. DONNAY, J-P.; KACZYNSKI, R. User's Guide. Dept of Geomatics, University of Liege, Belgium, Institute of Geodesy and Cartography (IGiK), Dept of Photogrammetry, Warszawa, Poland, 2005. 71 p.
5. Vilniaus miesto georeferencinès duomenuc bazès ir aerofototrianguliacijos sudarymas fotogrametriniu būdu. Mokslo darbo ataskaita. Vadovas A. Žalnierukas. VGTU Geodezijos institutas, $1997.70 \mathrm{p}$.

6. RUZGIENE, B.; KACZYNSKI, R. Photographic mission specification for mapping urban territories at a large scale. In The $6^{\text {th }}$ International Conference "Environmental Engineering”, Vol II. Vilnius: Technika, 2005, p. 9931005.

Birutė RUZGIENE். Associate Professor, Doctor.

Vilnius Gediminas Technical University, Dept of Geodesy and Cadastre, Sauletekio al. 11, LT-10223 Vilnius, Lithuania. $\mathrm{Ph}+3705274$ 4703, Fax +370 52744705 ,

e-mail: birute.ruzgiene@ap.vtu.lt.

A graduate of Vilnius Civil Engineering Institute (engineer of geodesy, 1968). Doctor (Vilnius Gediminas Technical University, 1999). Research training at Moscow Institute of Geodesy, Aerosurveying and Cartography (1986), at Norway AO Fjellanger Widerøe (1995), at Warsaw Institute of Geodesy and Cartography (1998), at Photogrammetry Institute of Bonn University (2000, 2005). Author of more than 30 scientific papers.

Research interests: digital photogrammetric mapping, image interpretation, features extraction from remote sensing data. 